Review Article

\title{
A Review of the Options to Restructure the System of Vietnam's Research and Development Organizations under the Impact of Policies
}

\author{
Khuat Thi Hong Duong* \\ Duy Phuong HB Limited Liability Company, Group 2, Ky Son, Hoa Binh, Vietnam
}

Received 28 October 2020

Revised 15 November 2020; Accepted 16 November 2020

\begin{abstract}
The network of R\&D organizations is a system and always a component of Vietnam national S\&T policy. According to the system pinciples, under the impact of the policy, this system has undergone numerous structure reforms to survive, develop and respond to the society's requirements. This article analyzes a number of variants that have been implemented by the state in the restructuring of the system of R\&D organizations in Vietnam.
\end{abstract}

Keywords: System of R\&D organizations, restructure, planning.

\footnotetext{
${ }^{*}$ Corresponding author.

Email address: khuathongduong272eya@gmail.com
}

https://doi.org/10.25073/2588-1116/vnupam.4272 


\title{
Nhìn lại một số phương án tái cấu trúc hệ thống tổ chức nghiên cứu và triển khai nước ta dưới tác động của chính sách
}

\author{
Khuất Thị Hồng Dương* \\ Công ty TNHH Duy Phương HB Tổ 2, Kỳ Sơn, Hòa Bình, Việt Nam \\ Nhận ngày 28 tháng 10 năm 2020 \\ Chỉnh sửa ngày 15 tháng 11 năm 2020; Chấp nhận đăng ngày 16 tháng 11 năm 2020
}

\begin{abstract}
Tóm tắt: Mạng lưới các tổ chức nghiên cứu và triển khai (NC\&TK) là một hệ thống và luôn là bộ phận hợp thành của chính sách KH\&CN quốc gia. Theo quy luật hệ thống, dưới tác động của các chính sách, hệ thống này đã trải qua nhiều lần tái cấu trúc để tồn tại, phát triển và đáp ứng các yêu cầu của xã hội. Bài viết này phân tích một số phương án đã được nhà nước thực hiện nhằm tái cấu trúc hệ thống tổ chức NC\&TK nước ta).
\end{abstract}

Tù khóa: Hệ thống, tổ chức NC\&TK, tái cấu trúc, quy hoạch.

\section{Mở đầu}

Hệ thống các tổ chức khoa học và công nghệ (KH\&CN) theo nghĩa rộng và các tổ chức nghiên cứu và triển khai (NC\&TK) theo nghĩa hẹp ở bất kỳ quốc gia nào luôn là bộ phận hợp thành của chính sách đổi mới, đóng vai trò quan trọng trong chính sách phát triển. Đơn giản là vì hệ thống này là tác nhân chủ yếu thực hiện hoạt động $\mathrm{KH \& CN}$ đồng thời cũng là tấm gương phản chiếu chính sách KH\&CN quốc gia với tư cách là đối tượng chính sách.

Hệ thống các tổ chức NC\&TK nước ta nói chung và phân hệ các tổ chức NC\&TK của nhà nước nói riêng lớn về số lượng (so sánh tương đối so với các nước trong khu vực) trải khắp các lĩnh vực $\mathrm{KH} \& \mathrm{CN}$ từ nghiên cứu cơ bản đến triển khai công nghệ trong sản xuất. Dàn trải như vậy, hệ thống này chỉ nhận được các khoản đầu tư hạn hẹp, cũng phân tán, dàn trải như bản thân nó.

Là một hệ thống, hệ thống các tổ chức NC\&TK nước ta có lịch sử phát triển phù hợp với quy luật tồn vong như bất kỳ một thực thể xã hội nào: nó có khả năng chịu tác động của chính sách mà không bị tan rã nhờ khả năng thích nghi và tự điều chỉnh. Chính nhờ khả năng này mà sau rất nhiều lần tái cấu trúc theo kiểu "sắp xếp", "ghép nối" nó vẫn tồn tại và phát triển tuy không được đánh giá như là một sự phát triển có hiệu quả. Mặc dù vậy, một số bộ phận hợp thành của nó đã phát triển tốt như những điểm trồi của hệ thống. Nói theo ngôn ngữ thông thường là: đã xuất hiện các "điển hình tiên tiến" cần nghiên cứu, nhân rộng.

Bài báo tiền hành phân tích tổng quan một số chính sách tái cấu trúc tác động tới hệ thống các tổ chức NC\&TK trong thời gian qua nhằm nhận diện các thành công và hạn chế trong việc thúc đẩy phát triển hệ thống này.

\section{Nhận dạng các loại hình tổ chức NC\&TK trong quá trình đổi mới từ 1986 đến nay ${ }^{1}$}

2.1. Quan niệm về chức năng của tổ chức $N C \& T K$

\footnotetext{
*Tác giả liên hệ.

Địa chi email: khuathongduong272eya@gmail.com
}

https://doi.org/10.25073/2588-1116/vnupam.4272

${ }^{1}$ Xem thêm: Nguyễn Văn Học, Phạm Quang Trí, Giáo trình tổ chức và quản lý mạng lưới các tổ chức NC\&TK - Báo cáo Tổng hợp đề tài cấp Bộ "Nghiên cứu giáo trình đào tạo bậc tiến sĩ về Quản lý Khoa học và công nghẹ̣”, 2016. 
Chức năng tổ chức NC\&TK tại các nước phát triển và trong khu vực bao gồm nghiên cứu khoa học, giảng dạy (đào tạo) và cung cấp các dịch vụ KH\&CN (theo nghĩa mà UNESCO đã quy ước) trong đó kể cả tư vấn cho chính phủ.

Về chức năng nghiên cứu: các tổ chức NC\&TK không phụ thuộc vào loại hình đều có quyền tiến hành các nghiên cứu trải dài từ nghiên cứu cơ bản qua nghiên cứu ứng dụng tới sản xuất thử nghiệm.

Về chức năng đào tạo: Tại các nước tư bản, trường đại học được coi là tổ chức nghiên cứu khoa học với các phòng thí nghiệm được trang bị không thua kém các trung tâm nghiên cứu quốc gia.

Về chức năng sản xuất: Rất ít tài liệu nói về chức năng sản xuất công nghiệp trong các tổ chức NC\&TK tại các nước phát triển và trong khu vực. Ở Việt Nam trong giai đoạn hiện nay, nhà nước đang khuyến khích đa dạng hoá hoạt động vì vậy chức năng sản xuất trở thành cần thiết xét theo cả khía cạnh ứng dụng, gắn trực tiếp với sản xuất lẫn khía cạnh "tồn tại”.

\subsection{Các loại hình tổ chức tổ chức NC\&TK}

Theo báo cáo của Văn phòng đăng ký hoạt động KH\&CN, tính đên hết năm 2015, tổng số tổ chức NC\&TK đã đăng ký hoạt động là 30.072 trong đó công lập là 1.410 , ngoài công lập là 1.597. Hệ thống tổ chức NC\&TK được tổ chức theo hình thức viện, trung tâm, trạm trại nghiên cứu khoa học. Hoạt động của hệ thống này bao quát tất cả các lĩnh vực khoa học và công nghệ và được đặt trực thuộc các bộ, cơ quan ngang bộ, cơ quan thuộc chính phủ, các đoàn thể quần chúng hoặc tư nhân. Các tổ chức NC\&TK được phân loại như sau:

2.2.1. Phân theo lĩnh vực khoa học và công nghệ:

\footnotetext{
${ }^{2}$ Không kể các tổ chức đã bị thu hồi giấy phép và các tổ chức có giấy phép đã hết thời hạn nhưng không đăng ký lại. Theo báo cáo của Đoàn giám sát - Ủy ban thường vụ Quốc hội thì hiện nay cả nước có gần 2.500 tổ chức khoa học và công nghệ, tăng 11,15 lần so với năm 1996.Cụ thể, có $1.111 \mathrm{KH \& CN}$ công lập gồm 594 tổ chức thuộc trung ương, 507 tổ chức thuộc địa phương, 02 viện Hàn
}

Theo cách phân chia này, Việt Nam có các tổ chức NC\&TK trong lĩnh vực:

Lĩnh vực KHTN chiếm khoảng 5\% tổng số, Lĩnh vực KHKTvà $\mathrm{CN}$ chiếm khoảng 53,3\% tổng số. Lĩnh vực KHNN chiếm khoảng 17,8\% tổng số. Lĩnh vực KHYD chiếm khoảng 5,2\% tổng số. Lĩnh vực KHXH\&NV chiếm khoảng $18,7 \%$ tồng số.

\subsubsection{Phân theo vùng và lãnh thổ:}

Hiện nay, số lượng các tổ chức NC\&TK tại các thành phố lớn (người ta hay gọi trung tâm tạo vùng) rất cao: Hà nội - hơn $80 \%$, TP. Hồ Chí Minh - $10 \%$, các tỉnh miền Trung - gần $5 \%$, Bắc bộ $83 \%$, Nam bộ - gần $12 \%$.

\section{Quá trình tái cấu trúc hệ thống tổ chức NC\&TK của Việt nam từ Nghị định 35-HĐBT năm 1992 đến nay}

\subsection{Các quan điểm chính trong tái cấu trúc hệ thống tổ chức NC\&TK ở nước ta}

Quan điểm thứ nhất: Tái cấu trúc hệ thống tổ chức NC\&TK là quá trình nâng cao hiệu quả hoạt động và giải phóng tiềm năng chất xám của hệ thống các tổ chức NC\&TK.

Quan điểm thứ hai: Hoạt động $K H \& C N$ là hoạt động mang tính xã hội do vậy cần được đa dạng hóa các tác nhân tham gia thực hiện hoạt động này. Mọi tác nhân đều có quyền tự do đầu tư, tổ chức thực hiện, sử dụng thành quả hoạt động NC\&TK không chỉ của mình mà còn cả các kết quả thu được trên cơ sở kinh phí từ ngân sách Nhà nước, theo quy định của pháp luật.

Quan điểm thứ ba: Tái cấu trúc hệ thống các tổ chức NC\&TK theo nguyên tắc thứ tư u'u tiên, gắn kết nghiên cứu với đào tạo và sản xuất, đa dạng hoá loại hình tổ chức các tổ chức $N \boldsymbol{C} \& \boldsymbol{T K}$ theo thành phần kinh tế kết hợp với đa dạng hoá loại hình hoạt động trong tổ chức

lâm (Viện Hàn lâm KH\&CN Việt Nam và Viện Hàn lâm KHXH Việt Nam), 02 đại học quốc gia (Đại học Quốc gia Tp. Hà Nội và Đại học Quốc gia Tp. Hồ Chí Minh), hơn 207 trường đại học (tính đến 31 tháng 12 năm 2014) 
NC\&TK trên cơ sở tôn trọng quyền tụ chủ cho các tổ chức NC\&TK.

3.2. Một số phuoong án tái cấu trúc hệ thống các tổ chức NC\&TK ở nước ta tù Nghi định 35HĐBT năm 1992 đến nay

3.2.1. Phương án theo Nghị định 35-HĐBT năm 1992 [1]

Phương án tái cấu trúc hệ thống tổ chức NC\&TK theo Nghị định 35-HĐBT (sau đây viết tắt là phương án 35-HĐBT) là phương án tự chuyển đổi dựa trên những biện pháp điều tiết bằng hệ thống các thiết chế. Phương án không nhằm giảm số lượng các tổ chức NC\&TK mà ngược lại trao quyền tự do thành lập cho tất cả các ngành, các cấp, các thành phần kinh tế, xã hội, mọi công dân trên cơ sở 4 tự: tự chủ tài chính, tự do liên kết, tự chủ hoạt động và tự chịu trách nhiệm trước pháp luật. Mọi hoạt động đều phải được đăng ký trước pháp luật và sau khi đăng ký sẽ được pháp luật bảo hộ.

Từ sau khi Nghị định 35-HĐBT được ban hành đến 2005, hệ thống tổ chức NC\&TK nước ta có 806 đơn vị, trong đó khoảng 240 thuộc thành phần kinh tế tập thể, tư nhân, 70 thuộc các trường đại học và cao đẳng và nhiều tổ chức phối thuộc, liên doanh liên kết trong, ngoài nước. Hình thức tổ chức NC\&TK tự trang trải do các Viện, Trung tâm, các trường đại học lập ra theo Nghị định 35-HĐBT suy cho cùng là hình thức "tổ chức NC\&TK cổ phần" hoặc tổ chức KH\&CN bán công và rất có thể sẽ xuất hiện "công khai" trong hệ thống thời gian tới. Quá trình này thực chất là quá trình cổ phần hoá tự phát. Chỉ có điều là trong quá trình cổ phần hoá tự phát này chúng ta chưa kịp phát hiện để quy định rạch ròi quyền sở hữu và sử dụng nguồn lực.

Phương án 35-HĐBT là phương án khả dĩ để tiến hành tái cấu trúc hệ thống các tổ chức NC\&TK ở Việt nam với tư tưởng chủ đạo là tự do hoá và tự chủ nguồn lực và tự chịu trách nhiệm trước pháp luật. Để thực hiện, trong phương án đã thiết kế một hệ thống các biện pháp chính sách đồng bộ. Nhưng do nhận thức, ý thức trách nhiệm, trình độ quản lý trong bối cảnh chuyển đổi nên không phải mọi nơi mọi lúc đều quán triệt tư tưởng này. Điều đó dẫn đến sự thiếu đồng bộ của hệ thống biện pháp tổ chức thực hiện trên thực tế. Rất không may sự thiếu đồng bộ này lại rơi vào chính sách tài chính và chính sách nhân lực - hai công cụ mang tính đột phá mà nguyên nhân sâu xa là do sự lệch pha giữa hệ thống quản lý kinh tế-xã hội với hệ thống quản lý $\mathrm{KH \& CN}$. Kết quả là hệ thống tổ chức NC\&TK với tư cách là đối tượng quản lý của cả hai hệ thống (hoặc trực tiếp hoặc gián tiếp) phải hứng chịu: cho đến nay nó vẫn bị coi là cồng kềnh, kém hiệu quả, thiếu liên kết

3.2.2. Phương án theo Nghị định 115/2005/NĐ-CP năm 2005 [2]

Theo báo cáo của Đoàn giám sát - Ủy ban thường vụ Quốc hội, trong số 1.111 tổ chức NC\&TK có 642 tổ chức NC\&TK công lập thuộc diện phải chuyển sang hoạt động theo hình thức tự chủ, tự chịu trách nhiệm (gồm 473 tổ chức thuộc các bộ, ngành và 169 tổ chức thuộc các tỉnh, thành phố trực thuộc Trung ương). Đến ngày 31/12/2014, có 488 tổ chức đã được phê duyệt Đề án thực hiện cơ chế tự chủ, tự chịu trách nhiệm (đạt $76 \%$ ), trong đó có 380 tổ chức thuộc các bộ, ngành và 108 tổ chức thuộc các tỉnh, thành phố trực thuộc Trung ương. Số liệu Bộ KH\&CN cho thấy đến năm 2016 về cơ bản các tổ chức NC\&TK công lập đã được phê duyệt đề án thực hiện cơ chế tự chủ.

Cần lưu ý rằng con số $76 \%$ và cụm từ "về cơ bản" chỉ nói lên là đã được phê duyệt đề án chuyển đổi chứ không phản ánh việc chuyển đổi thành công hay không thành công. Cũng cần phải nói thêm rằng, Nghị định 115/2005/NĐ-CP đã qua ít nhất 4 lần điều chỉnh (2 lần về thời gian thực hiện và 2 lần bổ sung các quy định). Còn nhiều bấp cập trong quá trình thực thi tái cấu trúc hệ thống các tổ chức NC\&TK theo phương án này. Một trong những bất cập mang tính "gốc rễ" là chưa quy định rõ ràng giữa sở hữu nhà nước và quyền sử dụng của các tổ chức NC\&TK công lập.

Đó là mâu thuẫn giữa một bên đề cao vai trò sở hữu của Nhà nước và một bên là tính tự quyền của tổ chức NC\&TK. Xuất hiện vấn đề quan hệ giữa chủ sở hữu và chủ sử dụng. Tính chất công 
hữu, toàn dân của quan hệ sở hữu đã trực tiếp chi phối quan hệ sử dụng. Với tư cách là chủ sở hữu, nhà nước muốn tăng cường vai trò điều tiết trực tiếp của mình, trong khi các tổ chức NC\&TK muốn được tự quyết sử dụng tài sản với tư cách là công cụ sản xuất mà thiếu nó không thể nói đến quyền tự chủ đúng nghĩa. Mâu thuẫn này đã và đang là vấn đề ngay cả trong tái cấu trúc hệ thống doanh nghiệp nhà nước, cho nên không ngạc nhiên vì sao việc thực hiện tái cấu trúc theo phương án theo Nghị định 115/2005/NĐ-CP lại khó khăn đến thế.

Mặc dù Vũ Cao Đàm (2017) [3] đã đánh giá Nghị định 115/2005/NĐ-CP như là tuyên ngôn của nhà nước về sự bắt đầu của triết lý 4 trong hệ thống $\mathrm{KH} \& \mathrm{CN}$ : "Mọi hoạt động KH\&CN đều được quyền tự trị (Autonomy), kể cả các hoạt động KH\&CN trong khuôn khổ các tổ chức KH\&CN do nhà nước thành lập". Thế nhưng, do không thể giải quyết trọn vẹn mâu thuẫn giữa sở hữu và sử dụng cộng với tâm lý không muốn mất "bộ hạ" để giữ "thần thiêng" nên phương án tái cấu trúc theo Nghị định 115/2005/NĐ-CP phân hệ tổ chức NC\&TK công lập vẫn còn dang dở

3.2.3. Phương án tái cấu trúc theo Quyết định 171/QĐ-TTg năm 2016

Thực chất, đây là Quy hoạch mạng lưới (phân hệ) các tổ chức NC\&TK công lập do thủ tướng quyết định thành lập [4]. Theo đó, trong thời gian từ $2016-2020$ có 133 tổ chức NC\&TK cấp quốc gia đặt trực thuộc các bộ và cơ quan ngang bộ, cơ quan thuộc Chính phủ. Đáng lưu ý theo phương án này có 03 tổ chức trực thuộc Đại học Quốc gia Hà Nội; 01 tổ chức trực thuộc Đại học Quốc gia thành phố Hồ Chí Minh. Với tính chất của Quy hoạch là cố định theo không gian và thời gian, từ 2016 đến 2020 số tổ chức NC\&TK cấp quốc gia sẽ cố định là 133 và sẽ được cắt giảm $30 \%$ (khoảng 40 tổ chức) đến năm 2030 nghĩa là sẽ có điều chỉnh quy hoạch theo hướng giảm đầu mối.

Ngoài ra, có trên dưới 1.000 các tổ chức NC\&TK công lập thuộc Ủy ban nhân dân tỉnh, thành phố trực thuộc Trung ương, các tổ chức, cơ quan nhà nước ra quyết định thành lập (không thuộc đối tượng điều chỉnh của Quyết định này).
Điều cần quan tâm khi thực hành phương án này, ít thấy những nét tái cấu trúc: Cơ cấu không thay đổi ngoại trừ thêm một vài viện tương ứng với chức năng của bộ chủ quản. Ví dụ, Viện Tài nguyên nước thuộc Bộ Tài nguyên và Môi trường, trong khi Viện Khoa học thủy lợi quốc gia đã nghiên cứu từ khi thành lập (1959) đến nay.

Cũng cần nói thêm rằng, việc Quy hoạch hệ thống các tổ chức NC\&TK nói chung và mạng lưới các tổ chức NC\&TK thuộc Chính phủ nói riêng lần đầu tiên được thực hiện ở nước ta. 133 Viện quốc gia cũng là con số lớn trong khi Hàn Quốc là 27, Indonesia 26, Singapore 16 v.v. Bên cạnh đó, bản chất của khoa học là luôn xuất hiện nhưng lĩnh vực mới đôi khi làm thay đổi triết lý phát triển và đối lập lại tính "cố định cứng theo không gian và thời gian" của quy hoạch. Chưa nói tới việc với xu thế internet kết nối vạn vật hiện nay thì quy hoạch theo không gian các tổ chức NC\&TK không nhiều ý nghĩa.

Nhận diện thực tế trên đây có thể giúp giải quyết những khó khăn nảy sinh trong quá trình thực hiện tái cấu trúc theo phương án 171/QĐTTg.

Cũng cần phải nói thêm rằng các phương án $35-\mathrm{HĐBT}$ và $115 / 2005 / \mathrm{NĐ-CP}$ có cùng chung một triết lý chính sách đó là quyền tự chủ, tự chịu trách nhiệm của các tổ chức NC\&TK, còn phương án 171/QĐ-TTg thực tế là một bản quy hoạch cứng theo thời gian và không gian. Các giải pháp chính sách mà Nghị định 35-HĐBT đưa ra được xem như là chính sách đổi mới với nghĩa là tập hợp có hệ thống các chính sách để quản lý hệ thống các tổ chức NC\&TK. Các giải pháp của 115/2005/NĐ-CP chủ yếu tập trung vào các thiết chế tài chính và tổ chức. Quyết định về sở hữu và sử dụng tài sản của các tổ chức NC\&TK không thể và không thuộc thẩm quyền ở cấp Nghị định của chính phủ. Giải pháp của 171/QĐ - TTg chủ yếu là giải pháp hành chính quy định mỗi bộ, cơ quan ngang bộ cơ quan thuộc Chính phủ có bao nhiêu tổ chức NC\&TK. 


\section{Kết luận}

Từ năm 1986 đến nay, có rất nhiều chính sách khác nhau tác động lên hệ thống các tổ chức $\mathrm{KH} \& \mathrm{CN}$ nói chung và hệ thống các tổ chức NC\&TK nói riêng. Có những tác động dương tính, có tác động tâm tính và có tác động ngoại biên. Nhưng với tư cách là hệ thống, hệ thống này luôn biến đổi để thích nghi, tồn tại và phát triển dưới những tác động đó. Một trong những thay đổi để thích nghi đó là tái cấu trúc. Chính sách các phương án trình bày trên đây đều nhằm khuyến khích sự thay đổi đó. Tuy nhiên, do môi trường chính sách của hệ thống lớn - hệ thống KT-XH chưa thật thuận lợi nên sự thành công của các phương án nêu trên còn hạn chế. Cho đến nay hoạt động của hệ thống các tổ chức NC\&TK nước ta vẫn còn dàn trải và chưa phát huy hết tiềm năng.

Để thay cho lời kết, tác giả muốn nói tới một xu thế đang đến gần: xu thế khoa học trị. Nó tồn tại ở phương Tây ngay từ khi các trường đại học ra đời ở Ý. Nhà nước có thể giao lại tài sản (vốn là công cụ của người lao động khoa học) có điều kiện cho tập thể khoa học sở hữu và sử dụng miễn sao không làm xáo động xã hội. Hãy để họ tự do, tự tại như người nông dân trên mảnh đất khoán, mặc dù hoạt động KH\&CN khác xa, rất xa so với hoạt động gieo cấy. Chẳng phải chúng ta đang muốn họ được như thế sao nhất là rất không muốn tiếp tục "nuôi" họ thuần túy bằng tiền ngân sách! Hãy phi "chủ quản" họ và thực hiện đánh giá qua việc họ làm cho chính mình và cho xã hội. Hệ giá trị sẽ thay đổi khi được tự do trong sự hỗ trợ bằng pháp luật của Nhà nước.

\section{Tài liệu tham khảo}

[1] Council of Minister, Decree 35-HDBT on Science and Technology Management (in Vietnamese), Hanoi, February 28, 1992.

[2] Government, Decree $115 / 2005 /$ ND-CP on the Mechanism of Autonomy and Self-Responsibility in Terms of Tasks, Finance and Assets, Organization and Payroll of Public Scientific and Technology Organizations (in Vietnamese), Hanoi, May 16, 2005.

[3] V.C Dam, Evaluation of Results and Proposing Solutions to Enhance the Implementation of Decree 115-2005/ND-CP on Autonomy and SelfResponsibility of Public Scientific and Technology Organizations and Decree 80-2007/ND-CP of the Government (in Vietnamese), 2017.

[4] Prime Minister, Decision No.171/QD-TTg Approving the Planning of the Network of Public Scientific and Technology Organizations to 2020, with a Vision to 2030 (in Vietnamese), Hanoi, January 27, 2016. 